\title{
Elder abuse: an approach to identification, assessment and intervention
}

\author{
Xuyi Mimi Wang MD, Sarah Brisbin MSc, Tenneille Loo MSc, Sharon Straus MD MSc
}

CMAJ Podcasts: author interview at soundcloud.com/cmajpodcasts/wang-elder-abuse

$\mathrm{E}$ lder abuse is increasingly recognized as an important problem associated with significantly increased rates of hospital admission, ${ }^{1}$ nursing home placement ${ }^{2}$ and mortality. ${ }^{3}$ Estimates of prevalence vary widely, but recent studies, including a 2008 systematic review, have suggested that $5 \%-10 \%$ of older adults report experiencing abuse. ${ }^{4,5}$

In December 2012, the Canadian Parliament passed Bill C-36, the Protecting Canada's Seniors Act, which aims to protect older adults through amendments to the Criminal Code. This bill makes elder abuse an aggravating factor for sentencing purposes, such that criminal acts of elder abuse might be subject to maximal sentencing. There is, however, a substantial discrepancy between prevalence estimates of elder abuse and the number of cases reported to police. In 2009, for example, Canadian police reported 7871 cases of violent crime against people 65 years of age or older ${ }^{6}$ (relative to a total population of over 4 million in that age group ${ }^{7}$ ). Justice Canada researchers have found that charges were laid in only $17 \%$ of cases of alleged elder abuse handled by Ottawa police between 2005 and $2010 .{ }^{8}$ These data suggest that many cases of elder abuse do not reach the criminal justice system and that physicians may be among the first who can intervene.

As populations age, it is becoming increasingly necessary for physicians to identify, assess and initiate management of elder abuse. Research into how best to do this is therefore of substantial importance.

The complexity of the issue, however, means that research into elder abuse is inherently challenging. For example, elder abuse is defined in various ways. The term encompasses multiple types of abuse, including physical, psychological, sexual and financial abuse, as well as neglect, each of which may be associated with different risk factors, mechanisms of causality and optimal interventional approaches. ${ }^{9-11}$ Moreover, many older adults who experience abuse are cognitively impaired, socially isolated and frail, and they may have complicated and dependent relationships with their abusers. ${ }^{12-14}$ Furthermore, the collection of sensitive information about abuse could have negative emotional, social, financial or legal consequences for multiple parties, leading both the abused older person and the abuser to actively try to hide the abuse. This raises ethical concerns about conducting research on a vulnerable population..$^{13,15,16}$

Given the challenges of conducting research in this topic area, there is little evidence to provide guidance on whether screening for abuse is effective and which interventions to manage the risk of abuse are effective. A previous systematic review of interventions for elder abuse showed the paucity of evidence. ${ }^{17}$ The current review (Box 1) updates that earlier systematic review; discusses definitions, risk factors, clinical manifestations and recommendations for screening for elder abuse; and offers an approach for clinicians to consider when assessing older adults at risk for abuse.

\section{How is elder abuse defined?}

The concept of elder abuse is not consistently defined across jurisdictions in Canada. The World Health Organization adopted the United Kingdom Action on Elder Abuse definition in 1995 and defines it as "a single or repeated act or lack of appropriate action, occurring within any relation-

\section{KEY POINTS}

- Elder abuse is common, affecting $5 \%-10 \%$ of older adults.

- There is insufficient evidence to recommend screening all older people for elder abuse and insufficient evidence to recommend any one intervention.

- However, physicians still need to address this relatively common health issue. An advocacy approach for suspected elder abuse is recommended.

- Following an assessment of capacity, physicians should educate the patient about elder abuse and direct him or her to local resources, including home care and respite agencies, legal services, shelters and government-supported elder-abuse and police services. 
ship where there is an expectation of trust which causes harm or distress to an older person."18

More specifically, abuse includes acts of both commission and omission, and encompasses physical abuse (acts with the intention of causing physical pain or injury, including hitting, kicking, slapping and pushing or the misuse of medications or restraints), psychological abuse (acts with the intention of causing emotional pain or injury, including humiliation, isolation and threats of harm or abandonment), sexual abuse (including any sexual act to which the older person has not consented, could not consent or was pressured into consenting), financial exploitation (the misappropriation of an older person's money or property, including theft, fraud and pressuring the person to make changes to wills or financial transactions) and neglect (the failure of a caregiver to meet the needs of a dependent older person, including withholding of medications, nutrition or adequate shelter). ${ }^{12,13,19}$

\section{Box 1: Evidence for this review}

We searched MEDLINE, Embase, CINAHL and PsycINFO from the earliest date available to August 30, 2013, using a variety of search terms, including "elderly," "abuse" and "mistreatment" (the full list of terms and the search strategy are available from the authors upon request). We included both primary research articles and relevant review articles, and we reviewed the reference lists of pertinent articles. We performed a systematic review of interventions for the management of elder abuse, the focus of our article, according to the same search strategy. A full description of our search and its findings, as well as details about the studies we found, is presented in Appendix 1 (available at www.cmaj .ca/lookup/suppl/doi:10.1503/cmaj.141329/-/DC1).

Box 2: Risk factors* for elder abuse identified in a recent systematic review ${ }^{14}$

Relating to the older person:

- Cognitive impairment

- Behavioural problems

- Psychiatric illness or psychological problems

- Functional dependence (requiring assistance with activities of daily living)

- Poor physical health or frailty

- Low income or wealth

- Trauma or past abuse

- Ethnicity (increased risk among nonwhites for overall abuse, African Americans for financial abuse and Canadian Aboriginals for physical and sexual abuse)

Relating to the perpetrator:

- Caregiver burden or stress

- Psychiatric illness or psychological problems

Relating to the relationship:

- Family disharmony with poor or conflictual relationships

Relating to the environment:

- Low social support

- Living with others (except in financial abuse)

*There is inconsistent evidence supporting some of these risk factors. See details in text.

\section{What are the risk factors for elder abuse?}

A recent systematic review (of medium methodologic quality) identified 13 risk factors for abuse among community-dwelling older adults (Box 2). ${ }^{14}$ The authors concluded that lack of consistency in definitions and measurement tools in this field limits the potency of the evidence and that further research is required.

However, the systematic review ${ }^{14}$ focused on positive findings of factors associated with abuse and did not address conflicting studies with negative results showing that the same factors were not associated with abuse. Physical impairment and functional dependency, for example, were included as significant risk factors in the systematic review overall, but multiple studies included in the review also showed conflicting results that were not addressed. One of these studies was a prospective study of 341 Canadian patients served by a health and social service agency, which found that needing help with activities of daily living was not a significant predictor of abuse..$^{20} \mathrm{~A}$ cross-sectional survey of 412 older adults in Nanjing, China, also showed that physical impairment was not a significant risk factor. ${ }^{21}$

A possible association between elder abuse and ethnicity is also inconsistent. For example, older nonwhite participants were more likely to be abused than white participants in a nine-year observational cohort study of 2812 communitydwelling older adults in Connecticut. ${ }^{22}$ That study involved linking the cohort with protective service records for elderly people, which might have introduced reporting bias that could have resulted in overestimation of the effect of ethnicity. A more recent population survey of 5777 older adults in the United States showed that race- and ethnicity-based differences in the risk of elder abuse were absent after controlling for income, health status and social support. ${ }^{23}$

There is also some evidence that living alone is a risk factor for abuse, including a crosssectional survey of 2039 older adults in rural China, who represented $91 \%$ of the entire population over age 60 in 17 villages. ${ }^{24}$ Another cross-sectional study, which involved 460 older adults in Spain, found that living with another person was a risk factor for abuse only if the other person had a mental illness or problems with alcohol or drug use. ${ }^{25}$

These seemingly conflicting results may reflect different study designs, populations and definitions of abuse, but they may also be due to differences in risk factors for each type of abuse. For example, a cross-sectional survey of 
676 older adults in Spain found that psychological abuse was associated with depressive symptoms, social isolation and bladder incontinence in the abused individual; neglect was associated with social isolation, use of social services and living alone; and financial abuse was associated with being single, age 85 years or older, and lower score on the Mini-Mental State Examination. ${ }^{26}$ Beach and colleagues ${ }^{27}$ found that African American older adults were at greater risk of financial and psychological abuse than nonAfrican Americans in a cross-sectional study of 903 community-dwelling older adults in Pennsylvania. In another cross-sectional study, which involved 3005 community-dwelling older adults across the US, Latino older adults were at lower risk of verbal and financial mistreatment than whites. ${ }^{28}$

These studies, which are summarized in Appendix 1 (available at www.cmaj.ca/lookup /suppl/doi:10.1503/cmaj.141329/-/DC1; see Part 3), suggest that, rather than attempting to study elder abuse as a whole, researchers may need to address each type of abuse individually. Most of the studies, however, were limited to selfreported abuse and did not use validated assessment tools for determining the presence of abuse.

\section{What are the clinical manifestations of elder abuse?}

The clinical manifestations of elder abuse are difficult to identify and vary by type of abuse. Dyer and colleagues ${ }^{29}$ conducted a nonsystematic literature review of forensic markers of elder abuse, defined as "factors that are relevant to medical and legal determinations of whether elder abuse or neglect has occurred." They identified a variety of clinical features, including inadequately explained or unusual locations for skin abrasions, lacerations, bruises and burns; spiral fractures of long bones and fractures at sites other than the wrist, hip or vertebrae in a nonalcoholic elderly person; malnutrition and dehydration; pressure ulcers; sexually transmitted infections or pain in the oral or anal-genital region; and vaginal or rectal bleeding without other reasonable explanation.

Some other reviews on elder abuse have included lists of possible clinical manifestations, both including and in addition to those discussed by Dyer and colleagues. ${ }^{29}$ However, we were unable to identify any primary studies reporting the prevalence or test characteristics of any symptoms or signs of elder abuse. There is thus poor evidence to support any of these markers.

\section{Are there recommendations for screening or case-finding for elder abuse?}

In its 2013 systematic review for recommendations on elder abuse screening, the US Preventive Services Task Force ${ }^{30}$ included only the Elder Abuse Suspicion Index. This two-minute, sixitem questionnaire featuring dichotomous variables (Box 3) was administered in private by family physicians to cognitively intact older adults in a primary care setting in Montréal. ${ }^{31}$ When compared with a blinded social work assessment for identifying abuse, one or more positive responses on the Elder Abuse Suspicion Index had a sensitivity of $47 \%$ and a specificity of $75 \%$. There was also an enthusiastic response to the index from family physicians in a post-study survey, which suggests its acceptability. Given the lack of studies on screening instruments, however, the US Preventive Services Task Force concluded that there was insufficient evidence to assess the balance between benefits and harms of screening all elderly adults for abuse and neglect, and the task force was therefore unable to make a recommendation about screening for the general elderly population. ${ }^{30}$ The risk-benefit profile for screening in higher-risk populations is likely more in favour of screening, although there is no supporting evidence for this assumption.

\section{Box 3: Elder Abuse Suspicion Index ${ }^{31}$}

Questions 1-5 are asked of the patient and may be answered "Yes," "No" or "Did not answer." Question 6 is answered by the physician and may be answered "Yes," "No" or "Not sure."

Within the past 12 months:

1. Have you relied on people for any of the following: bathing, dressing, shopping, banking or meals?

2. Has anyone prevented you from getting food, clothes, medication, glasses, hearing aids or medical care or from being with people you wanted to be with?

3. Have you been upset because someone talked to you in a way that made you feel shamed or threatened?

4. Has anyone tried to force you to sign papers or to use your money against your will?

5. Has anyone made you afraid, touched you in ways that you did not want or hurt you physically?

6. Doctor: Elder abuse may be associated with findings such as poor eye contact, withdrawn nature, malnourishment, hygiene issues, cuts, bruises, inappropriate clothing or medication compliance issues. Did you notice any of these today or in the past 12 months?

Note: Answering Yes to one or more of questions 1 through 6 has a sensitivity of $47 \%$ and a specificity of $75 \%$ for elder abuse when compared with a blinded social work assessment. ${ }^{31}$

@ 2008 Mark J. Yaffe (mark.yaffe@mcgill.ca), Maxine Lithwick (maxine.lithwick.cvd@ssss.gouv. qc.ca), Christina Wolfson (christina.wolfson@mcgill.ca) and Taylor \& Francis Ltd. Reproduced by permission of the original authors and the publisher (Taylor \& Francis, www.tandfonline .com). Additional information about the Elder Abuse Suspicion Index is available at www .mcgill.ca/familymed/research-grad/research/projects/elder 
Other screening and assessment instruments for elder abuse include the Indicators of Abuse Screen, a 29-item checklist of problems that requires a two- to three-hour home visit by a trained health care provider (not necessarily a physician), which discriminated $84.4 \%$ of abuse cases and $99.2 \%$ of nonabuse cases in a validation study; ${ }^{20}$ the Elder Assessment Instrument, a 44-item Likert-scale checklist with a sensitivity of $71 \%$ and specificity of $93 \%$ when used in the emergency department by trained nurses ${ }^{32}$ and its updated revision, the Elder Assessment Instrument - Revised, a 51-item Likert-scale checklist ${ }^{33}$ and the Brief Abuse Screen for the Elderly, which contains five questions, requires less than a minute to complete and has $86 \%$ 90\% agreement among trained health care workers (not necessarily physicians). ${ }^{34} \mathrm{We}$ were unable to find data on the sensitivity and specificity of the Brief Abuse Screen for the Elderly. With the exception of the Elder Abuse Suspicion Index, none of these instruments has been validated in the primary care setting.

The most recent recommendations from the Canadian Task Force on Preventive Health Care are from 1994, at which time the task force found poor evidence to include casefinding for elder abuse in, or to exclude it from, the periodic health examination. ${ }^{35}$ The task force did, however, note that physicians should be alert for evidence suggestive of elder abuse that becomes apparent during history-taking and physical examination, such as positive answers to questions about the patient being forced to do things, being asked to sign documents he or she did not understand or being afraid; inconsistent histories from the patient and caregiver; long delays between injuries and seeking medical attention; and physical findings such as injuries in the shape of a weapon. Whenever possible, assessments of elder abuse should occur in private, as the presence of caregivers may hinder disclosure of abuse. The task force also suggested an advocacy approach to prevent further abuse, whereby physicians direct the older person to community resources. ${ }^{35}$

\section{What evidence supports interventions to combat elder abuse?}

Interventions can be categorized by the target (the abuser, the abused elderly person or the situation) (see Appendix 1, Part 4). All of the studies we identified ${ }^{36-45}$ were heterogeneous and had substantial limitations, and it is therefore difficult to recommend any of the studied interventions.
The most promising model is that of multidisciplinary teams that include physicians, nurses, mental health care providers, protective services and professionals within the justice system. However, there has been only one study demonstrating a statistically significant measurable outcome for a multidisciplinary team. ${ }^{45}$ This was a case-control study of the Los Angeles County Elder Abuse Forensic Center $(n=287)$, which showed increased rates of prosecution for financial abuse with a multidisciplinary team. This study addressed only financial abuse, however, and its results cannot be extrapolated to other types of abuse that may be harder to prove in the justice system. More fundamentally, it remains unclear what should be considered an effective outcome and whether abused elderly people view prosecution in a positive way.

\section{How can physicians intervene in clinical practice?}

Despite the lack of robust evidence to support recommendations, clinicians still need an approach to this relatively common problem. We encourage physicians to be aware of potential risk factors and clinical manifestations of elder abuse while recognizing the limitations of the research in this area. We also encourage physicians to consider using the Elder Abuse Suspicion Index (Box 3) for older patients with risk factors for abuse, to discuss privately with the patient any concerns, to assess the patient's decision-making capacity with regard to any proposed intervention and to consider referral to social service agencies or reporting to legal authorities, particularly in jurisdictions where adult protection laws mandate such reporting.

In the US, all but five states have some sort of mandatory reporting of elder abuse to adult protective services. According to the American Bar Association, however, "laws governing reporting are very diverse in content and structure and extremely challenging to categorize and explain." ${ }^{46}$ Adult protection laws in Canada similarly vary by province and territory. For example, Nova Scotia and Newfoundland and Labrador mandate that any person suspecting elder abuse is to report it without discriminating between capable or incapable older adults, whereas other provinces limit reporting to professional persons or have laws that vary according to whether the abused older person lives in a health care facility. ${ }^{47}$

Although there is no comparable Canadian statement, the Department of Health for England has issued a government policy statement on safeguarding vulnerable adults, ${ }^{48}$ which high- 
lights six principles: empowerment (presumption of person-led decisions and informed consent), prevention (it is better to take action before harm occurs), proportionality (proportionate and least intrusive response appropriate to the risk presented), protection (support and representation for those in greatest need), partnership (local solutions through services working with their communities) and accountability (accountability and transparency in delivery of safeguarding). With these principles in mind and on the basis of our experience and review of the literature, we propose the approach outlined in Figure 1. This approach has not been tested.

Assessment of suspected elder abuse should begin with an assessment of capacity. We believe that management strategies for elder abuse should be handled similarly to other medical treatment decisions with regard to capacity, namely whether the patient is able to understand and appreciate the consequences of the proposed treatment. If it is determined that the abused older person is capable, we suggest that the physician present his or her concerns about abuse to the patient, educate the patient about elder abuse and the tendency for it to increase in frequency and severity, and direct the patient to local resources, including day programs, home care, respite care, legal services, shelters and government-supported elder abuse consultants. In Canada, additional resources include the Advocacy Centre for the Elderly (www.advocacycentreelderly.org), the Canadian Network for Prevention of Elder Abuse (www.cnpea.ca), the Seniors Issues Unit of the Ontario Provincial Police (www.opp.ca/ecms /index.php?id=151) and the Royal Canadian Mounted Police (www.rcmp-grc.gc.ca/ccaps-spcca /elder-aine-eng.htm). Imminent safety should be assessed and any concerns clearly communicated to the patient, including creation of an emergency

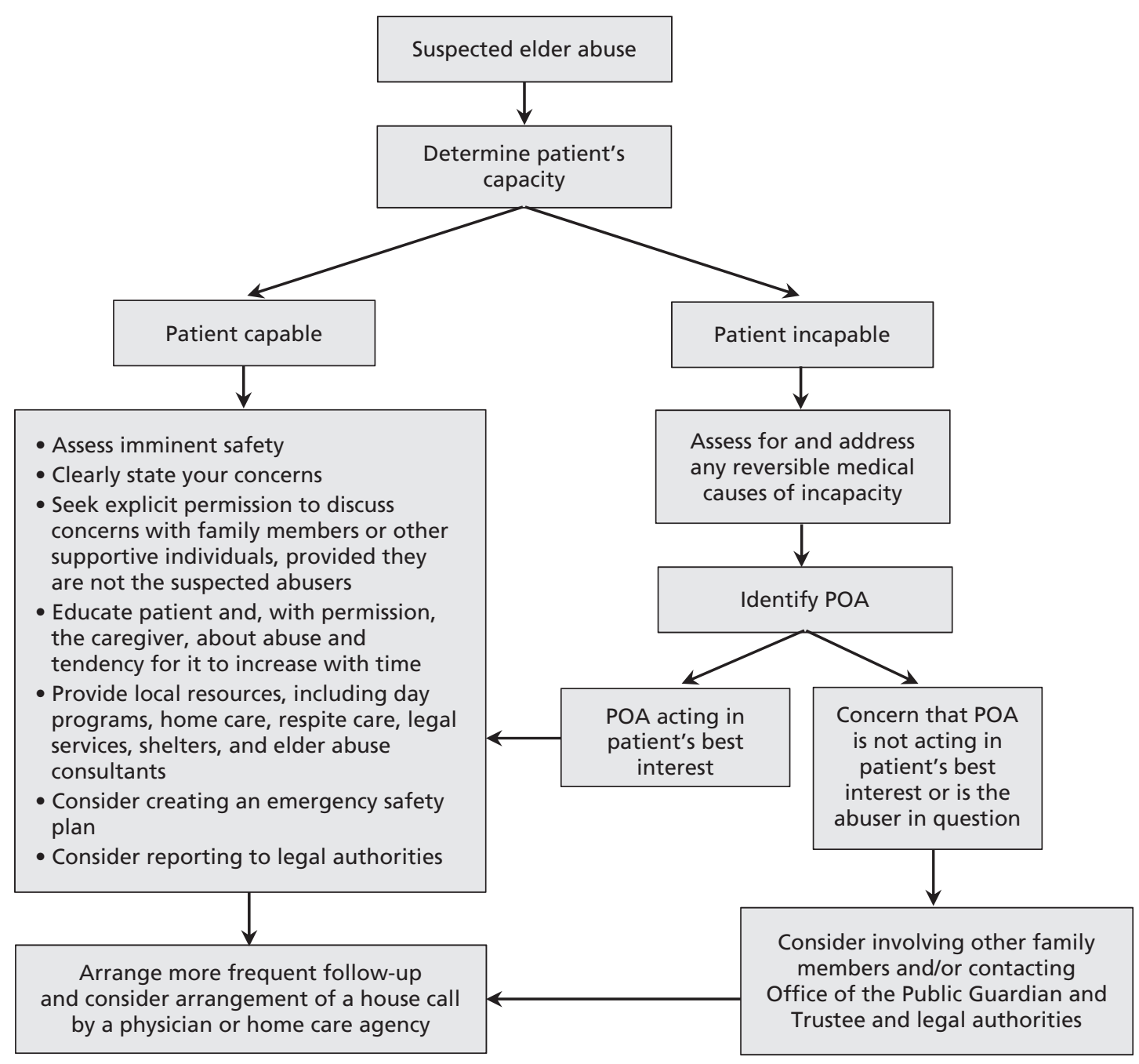

Figure 1: Suggested approach to intervening in cases of suspected elder abuse. POA = power of attorney. 
safety plan. Respecting the capable older person's autonomy should be a priority, however, and explicit permission should be sought before discussing any concerns with family members or caregivers who may be able to offer support to the older person.

In the case of an incapable older person who is experiencing abuse, we suggest identifying the person who has power of attorney and offering the same resources. Should there be concern that the person with power of attorney is not acting in the patient's best interest or is the abuser in question, alternative strategies such as liaising with social service agencies, contacting other family members or guardianship through the Office of the Public Guardian and Trustee should be considered. An important caveat would be to ensure that the incapable patient does not have reversible medical causes of incapacity that could be addressed before seeking guardianship. All abused older adults should be offered more frequent medical follow-up.

\section{Conclusion}

Evidence regarding the risk factors for, assessment of and interventions to address elder abuse is limited. Although multidisciplinary teams have existed for several decades, only one study has demonstrated a measurable effect of such teams, and it was limited to financial abuse. Elder abuse is probably best considered as a syndrome, similar to the other "geriatric giants"49 such as falls and frailty, given its complexity. ${ }^{12,50}$ The best intervention strategy at this time appears to be education targeted at increasing awareness of elder abuse among health care professionals, ${ }^{12,51}$ analogous to the incorporation of child abuse training into the medical school curriculum.

Future research is needed to clarify the risk factors for each type of abuse, to determine screening or case-finding thresholds, to define effective outcome measures and to test the efficacy of clinically feasible interventional approaches.

\section{References}

1. Dong X, Simon MA. Elder abuse as a risk factor for hospitalization in older persons. JAMA Intern Med 2013;173:911-7.

2. Lachs MS, Williams CS, O'Brien S, et al. Adult protective service use and nursing home placement. Gerontologist 2002;42: 734-9.

3. Lachs MS, Williams CS, O'Brien S, et al. The mortality of elder mistreatment. JAMA 1998;280:428-32.

4. Acierno R, Hernandez MA, Amstadter AB, et al. Prevalence of and correlates of emotional, physical, sexual, and financial abuse and potential neglect in the United States: the National Elder Mistreatment Study. Am J Public Health 2010;100:292-7.

5. Cooper C, Selwood A, Livingston G. The prevalence of elder abuse and neglect: a systematic review. Age Ageing 2008;37:151-60.

6. Senior victims (65 years and older) of violent crime by sex and accused-victim relationship, Canada, 2009. Ottawa: Statistics Canada; modified 2012. Available: www.statcan.gc.ca/pub/85-224 -x/2010000/t016-eng.htm (accessed 2014 July 10).
7. National Seniors Day ... by the numbers. Ottawa: Statistics Canada; 2014. Available from: www.statcan.gc.ca/dai-quo/smr08 12014/smr08_191_2014-eng.htm\#a1 (accessed 2014 Mar. 26).

8. Ha L, Code R. An empirical examination of elder abuse: review of files from the Elder Abuse Section of the Ottawa Police Service. Ottawa: Department of Justice; 2013. Available: www .justice.gc.ca/eng/rp-pr/cj-jp/fv-vf/rr13_1/rr13_1.pdf (accessed 2014 July 10)

9. Mysyuk Y, Westendorp RG, Lindenberg J. Added value of elder abuse definitions: a review. Ageing Res Rev 2013;12:50-7.

10. Daly JM, Merchant ML, Jogerst GJ. Elder abuse research: a systematic review. J Elder Abuse Negl 2011;23:348-65.

11. Yaffe MJ, Tazkarji B. Understanding elder abuse in family practice. Can Fam Physician 2012;58:1336-40.

12. Lachs MS, Pillemer K. Elder abuse. Lancet 2004;364:1263-72.

13. Swagerty DL Jr, Takahashi PY, Evans JM. Elder mistreatment Am Fam Physician 1999;59:2804-8.

14. Johannesen M, LoGiudice D. Elder abuse: a systematic review of risk factors in community-dwelling elders. Age Ageing 2013; 42:292-8

15. Levine JM. Elder neglect and abuse: a primer for primary care physicians. Geriatrics 2003;58:37-40.

16. Fulmer T. Barriers to neglect and self-neglect research. $J$ Am Geriatr Soc 2008;56(Suppl 2):S241-3.

17. Ploeg J, Hutchison B, MacMillan H, et al. A systematic review of interventions for elder abuse. J Elder Abuse Negl 2009;21:187-210.

18. A global response to elder abuse and neglect: building primary health care capacity to deal with the problem worldwide: main report. Geneva: World Health Organization; 2008. Available: http://whqlibdoc.who.int/publications/2008/9789241563581_eng .pdf (accessed 2013 Dec. 23).

19. Boland B, Burnage J, Chowhan H. Safeguarding adults at risk of harm. BMJ 2013;346:f2716.

20. Reis M, Nahmiash D. Validation of the indicators of abuse (IOA) screen. Gerontologist 1998;38:471-80.

21. Dong X, Simon MA. Is impairment in physical function associated with increased risk of elder mistreatment? Findings from a community-dwelling Chinese population. Public Health Rep 2010;125:743-53.

22. Lachs MS, Williams C, O'Brien S, et al. Risk factors for reported elder abuse and neglect: a nine-year observational cohort study. Gerontologist 1997;37:469-74.

23. Alexandra Hernandez-Tejada M, Amstadter A, Muzzy W, et al. The national elder mistreatment study: race and ethnicity findings. J Elder Abuse Negl 2013;25:281-93.

24. Wu L, Chen $\mathrm{H}, \mathrm{Hu} \mathrm{Y}$, et al. Prevalence and associated factors of elder mistreatment in a rural community in People's Republic of China: a cross-sectional study. PLoS One 2012;7:e33857.

25. Pérez-Cárceles MD, Rubio L, Pereniguez JE, et al. Suspicion of elder abuse in South Eastern Spain: the extent and risk factors. Arch Gerontol Geriatr 2009;49:132-7.

26. Garre-Olmo J, Planas-Pujol X, Lopez-Pousa S, et al. Prevalence and risk factors of suspected elder abuse subtypes in people aged 75 and older. J Am Geriatr Soc 2009;57:815-22.

27. Beach SR, Schulz R, Castle NG, et al. Financial exploitation and psychological mistreatment among older adults: differences between African Americans and non-African Americans in a population-based survey. Gerontologist 2010;50:744-57.

28. Laumann EO, Leitsch SA, Waite LJ. Elder mistreatment in the United States: prevalence estimates from a nationally representative survey. J Gerontol B Psychol Sci Soc Sci 2008;63:S248-54.

29. Dyer CB, Connolly MT, McFeeley P. The clinical and medical forensics of elder abuse and neglect. In: Bonnie RJ, Wallace RB, editors. Elder mistreatment: abuse, neglect and exploitation in an aging America. Washington: The National Academies Press; 2002. p. 339-81.

30. Moyer VA; US Preventive Services Task Force. Screening for intimate partner violence and abuse of elderly and vulnerable adults: US Preventive Services Task Force recommendation statement. Ann Intern Med 2013;158:478-86.

31. Yaffe MJ, Wolfson C, Lithwick M, et al. Development and validation of a tool to improve physician identification of elder abuse: the Elder Abuse Suspicion Index (EASI). J Elder Abuse Negl 2008;20:276-300.

32. Fulmer T, Paveza G, Abraham I, et al. Elder neglect assessment in the emergency department. J Emerg Nurs 2000;26:436-43.

33. Fulmer T, Strauss S, Russell SL, et al. Screening for elder mistreatment in dental and medical clinics. Gerodontology 2012; 29:96-105.

34. Reis M, Nahmiash D. When seniors are abused: an intervention model. Gerontologist 1995;35:666-71.

35. Canadian Task Force on the Periodic Health Examination. Periodic health examination, 1994 update: 4 . Secondary prevention of elder abuse and mistreatment. CMAJ 1994;151:1413-20. 
36. Brownell P, Wolden A. Elder abuse intervention strategies: Social service or criminal justice? J Gerontol Soc Work 2002;40: 83-100.

37. Sengstock MC, Hwalek M, Stahl C. Developing new models of service delivery to aged abuse victims: Does it matter? Clin Sociol Rev 1991;9:142-61.

38. Filinson R. An evaluation of a program of volunteer advocates for elder abuse victims. J Elder Abuse Negl 1993;5:77-93.

39. Wolf RS, Pillemer KA. Helping elderly victims: the reality of elder abuse. New York: Columbia University Press; 1989.

40. Ernst JS, Smith CA. Assessment in adult protective services: Do multidisciplinary teams make a difference? J Gerontol Soc Work 2012;55:21-38.

41. Pillemer K, Hudson B. A model abuse prevention program for nursing assistants. Gerontologist 1993;33:128-31.

42. Drossel C, Fisher JE, Mercer V. A DBT skills training group for family caregivers of persons with dementia. Behav Ther 2011;42:109-19.

43. Hsieh HF, Wang JJ, Yen M, et al. Educational support group in changing caregivers' psychological elder abuse behavior toward caring for institutionalized elders. Adv Health Sci Educ Therory Practc 2009; 14:377-86.

44. Reay AM, Browne KD. The effectiveness of psychological interventions with individuals who physically abuse or neglect their elderly dependents. J Interpers Violence 2002;17:416-31.

45. Navarro AE, Gassoumis ZD, Wilber KH. Holding abusers accountable: an elder abuse forensic center increases criminal prosecution of financial exploitation. Gerontologist 2013;53:303-12.

46. Stiegl L, Klem E. Explanation of the "reporting requirements: provisions and citations in adult protective services laws, by state" and "mandatory reporters: comparison charts of categories in adult protective services laws, by state" charts. Chicago: American Bar Association, Commission on Law and Aging; 2008. Available: www.americanbar.org/content/dam/aba /migrated/aging/docs/MandatoryReportingChartsExplanation .authcheckdam.pdf (accessed 2014 July 8).
47. A practical guide to elder abuse and neglect law in Canada. Vancouver: Canadian Centre for Elder Law; 2011. Available: www.bcli.org/sites/default/files/Practical_Guide_English_Rev _JULY_2011.pdf (accessed 2013 Dec. 23).

48. Adult safeguarding: updated statement of government policy. London: Department of Health of England; 2013. Available: https://www.gov.uk/government/publications/adult-safeguarding -statement-of-government-policy-10-may-2013 (accessed 2015 Mar. 26).

49. Isaacs B. An introduction to geriatrics. Baltimore: Williams \& Wilkins; 1965.

50. Dong $\mathrm{X}$, Chen R, Chang ES, et al. Elder abuse and psychological well-being: a systematic review and implications for research and policy - a minireview. Gerontology 2013;59:132-42.

51. Cooper C, Selwood A, Livingston G. Knowledge, detection, and reporting of abuse by health and social care professionals: a systematic review. Am J Geriatr Psychiatry 2009;17:826-38.

Affiliations: Division of Geriatric Medicine (Wang), McMaster University, Hamilton, Ont.; Faculty of Medicine (Brisbin, Loo) and Division of Geriatric Medicine (Straus), University of Toronto, Toronto, Ont.; Li Ka Shing Knowledge Institute (Straus), St. Michael's Hospital, Toronto, Ont.

Contributors: Xuyi Mimi Wang was involved in the conception and design of the review, literature search, abstract review, full-text review, data abstraction, and drafting and editing of the manuscript. Sarah Brisbin was involved in the abstract review, full-text review, data abstraction and manuscript editing. Tenneille Loo was involved in abstract review and manuscript editing. Sharon Straus was involved in the conception and design of the review, literature search and manuscript editing. All of the authors gave final approval of the version to be published and agree to act as guarantors of the work.

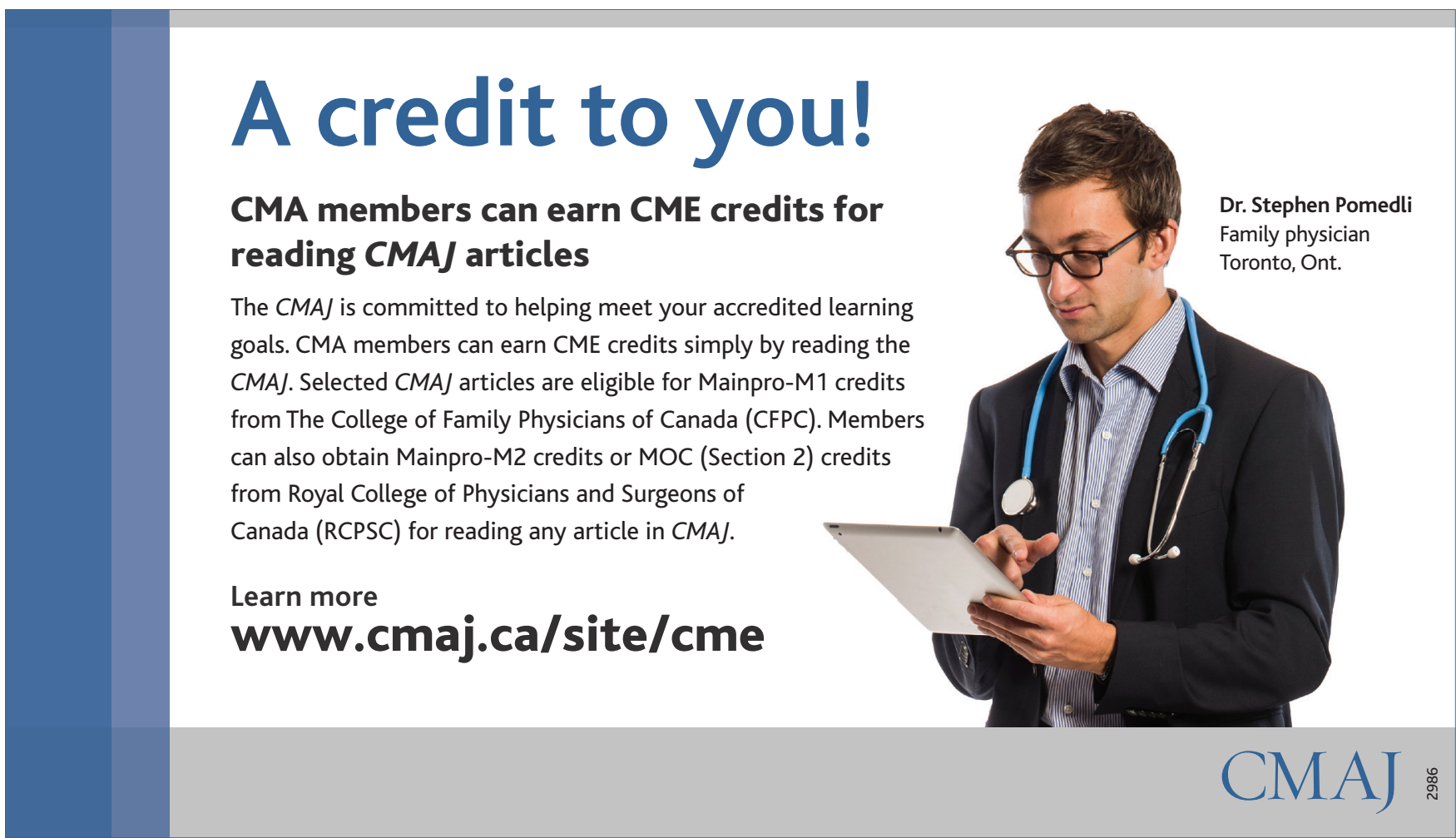


"ClinicalKey has become an essential complement to DynaMed and UpToDate when I am at my patient's bedside."

Dr. Pierre Harvey

Microbiologist and infectious disease specialist Rivière-du-Loup, Que.

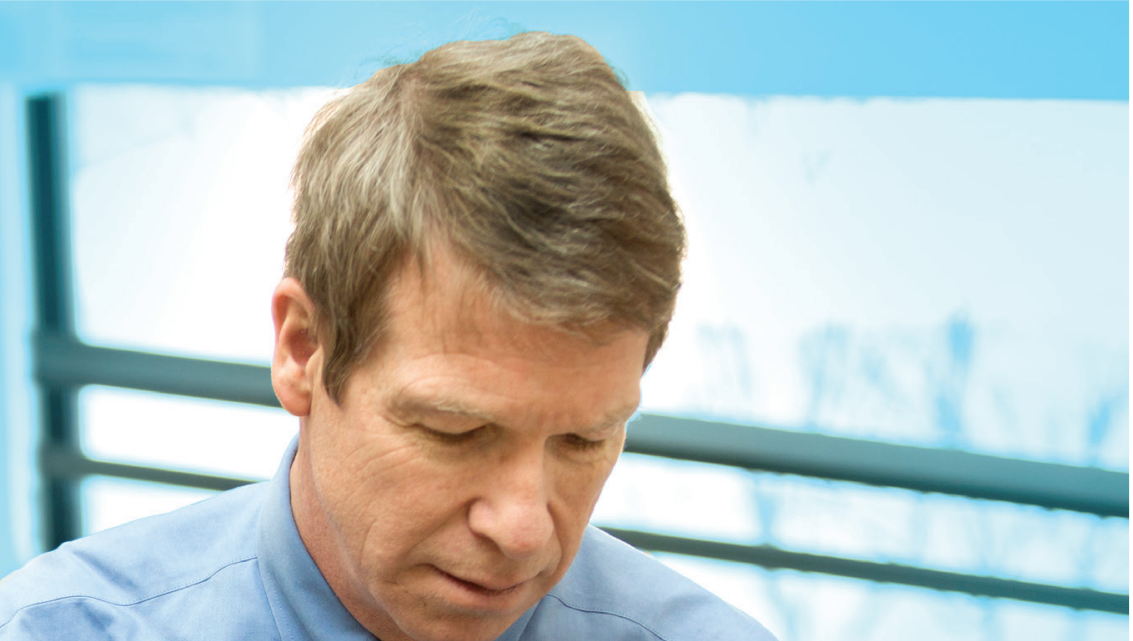

CMA membership now includes access to ClinicalKey

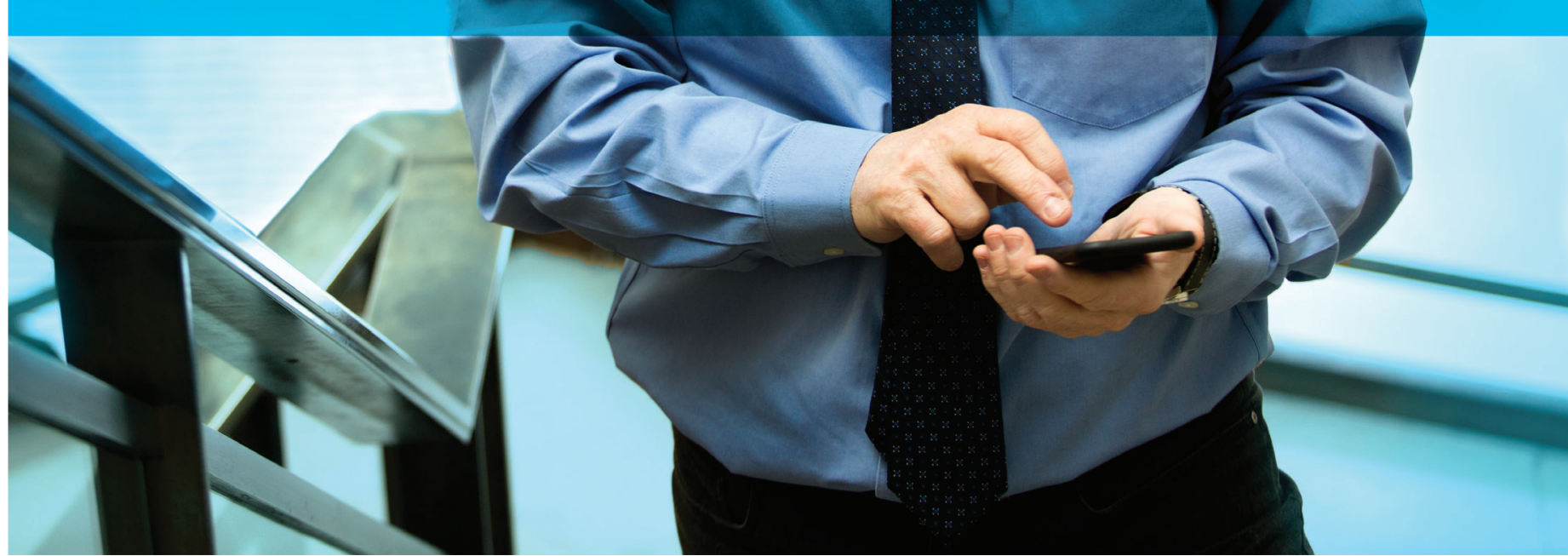

Drive decision-making with a clinical search engine that gives you quick access to better evidence

\section{TRUSTED}

Access clinical answers and

trusted evidence

\section{LEADING}

Search current resources across

$30+$ medical specialties
CONVENIENT Use anywhere, anytime at the bedside or on the go

Another valuable CMA member benefit that saves you up to $\$ 1,200$ a year* — Start searching today

\section{cma.ca/clinicalkey}

